\title{
Advances in research on the effects of platelet activation in acute lung injury (Review)
}

\author{
YUAN XIN*, JIANG PENG*, YU YUN HONG, QIAO CONG CHAO, \\ SU NA, SUN PAN and LIN FANG ZHAO \\ Institute of Blood Transfusion, Chinese Academy of Medical Science and \\ Peking Union Medical College, Chengdu, Sichuan 610052, P.R. China
}

Received November 22, 2021; Accepted January 5, 2022

DOI: $10.3892 /$ br.2022.1500

\begin{abstract}
Acute lung injury (ALI) is an acute hypoxic respiratory insufficiency or failure caused by various factors inside and outside the lungs. ALI is associated with high morbidity and a poor prognosis in hospitalized patients. The lungs serve as a reservoir for platelet precursor megakaryocytes and are closely associated with platelets. Platelets not only play a central role in hemostasis, coagulation and wound healing, but can also act as inflammatory cells capable of stimulating non-hemostatic immune functions under inflammatory conditions, participating in the progression of various inflammatory diseases, and can result in tissue damage. Therefore, it was speculated that platelets may play an important role in the pathogenesis of ALI. In this review, the latest research progress on secretion of bioactive mediators from platelets, platelet activation-related signaling pathways, and the direct contact reactions between platelets and neutrophils with endothelial cells that result in ALI are described, providing evidence to support the importance of the consideration of platelets in the search for ALI interventional targets.
\end{abstract}

\section{Contents}

1. Introduction

2. Advances in the pathogenesis of acute lung injury and interventional treatment

3. Platelets and inflammatory diseases

4. Platelet activation is involved in the pathogenic mechanism of ALI

5. Conclusion and future prospects

Correspondence to: Professor Lin Fang Zhao, Institute of Blood Transfusion, Chinese Academy of Medical Science and Peking Union Medical College, 26 Huacai Road, Chengdu, Sichuan 610052, P.R. China

E-mail: fangzhao.lin@ibt.pumc.edu.cn

*Contributed equally

Key words: acute lung injury, platelets, inflammation, mechanism of injury

\section{Introduction}

Acute lung injury (ALI) is an injury to the pulmonary capillary endothelial cells and pulmonary epithelial cells following severe infection, shock, trauma or major surgery, resulting in diffuse interstitial lung infiltration and noncardiogenic pulmonary edema. This can ultimately result in acute hypoxic respiratory insufficiency or failure (1), which can be a serious threat to a patient's health. The global incidence of ALI ranges from $7.2 / 100,000$ to $78.9 / 100,000$, with a mortality rate of $\sim 40 \%$ and persistent pulmonary dysfunction occurs in $\sim 50 \%$ of survivors, which in-turn results in significant social implications and financial burdens (2). Despite the notable growth in the understanding of ALI over the past few decades, several aspects remain unknown; there are no reliable diagnostic measures to accurately identify individuals at risk of ALI, and there are no effective interventional measures or treatments that have been shown to prevent its occurrence. Researching the pathogenesis of ALI could help to provide novel interventional and treatment strategies for management of ALI, which may result in reduced mortality rates and an improved quality of life for patients, whilst also reducing the economic burden. In recent years, in addition to the widely recognized role of platelets in thrombosis and hemostasis, several researchers have focused on their involvement in the inflammatory process as immune cells (3-6). The following is a review of the relevance of platelet involvement in the development of ALI based on the possible factors involved in the progression of inflammation after platelet activation, with the aim of identifying therapeutic directions for targeting ALI through the inhibition of platelet pathways.

\section{Advances in the pathogenesis of acute lung injury and interventional treatment}

ALI has several causative factors, including those that can directly affect the development of infection in the lungs, such as accidental aspiration of gastric contents, pulmonary contusion, inhalation of toxic gases, drowning and oxygen toxicity. Moreover, other factors can indirectly lead to pulmonary infection, such as severe non-thoracic trauma, acute severe pancreatitis, massive blood transfusion, extracorporeal circulation and diffuse intravascular coagulation (7). The pathology 
of ALI can be divided into two components, impaired gas exchange and inflammatory damage. In the acute phase of ALI, the alveolar-capillary barrier, consisting of the vascular endothelium, mesenchyme and alveolar epithelium, is damaged, resulting in increased vascular and alveolar epithelial permeability and the flow of protein-rich fluid into the interstitium and alveoli, leading to impaired gas exchange (8). Following the occurrence of ALI, numerous inflammatory cells are activated and induce the production of several cytokines and inflammatory mediators, such as IL-6, IL-8 and TNF- $\alpha$ (9), which cause further damage to the body. The development of ALI involves complex regulatory mechanisms, and several experiments have demonstrated the central role of inflammation in the progression of ALI $(10,11)$. The majority of studies have focused on the recruitment and activation of neutrophil adhesion. For example, Bhatia et al (12) reported that inflammation initiates chemokine-driven neutrophil activation, followed by neutrophil-derived production of reactive oxygen species and proteases, among other molecules, which cause damage to tissue cells; Saffarzadeh et al (13) demonstrated that neutrophils directly induce epithelial and endothelial cell death through activation of the p38 MAP kinase pathway and the Raf-MEK-ERK kinase pathway, resulting in lung injury; Jeyaseelan et al (14) suggested that hyaluronic acid produced by damaged tissues binds to Toll-like receptor (TLR) 4 to initiate the inflammatory response in acute respiratory distress syndrome (ARDS) and that the TLR pathway activates lung macrophages, which release pro-inflammatory mediators and trigger an inflammatory cascade that activates and leads to the chemotaxis of neutrophils and other inflammatory cells to the airways. In addition, certain signaling pathways also act directly on neutrophils to regulate their role in the development of ALI, as suggested by the study by Huang et al (15), who demonstrated that hypoxia-inducible factor $1 \alpha$ may regulate the activation of NOD-like receptor protein 3 inflammatory vesicle activation and thus regulate ALI.

\section{Platelets and inflammatory diseases}

Platelets are small pieces of cytoplasm shed from mature megakaryocytes in the bone marrow, and contain glycogen, mitochondria and at least three types of granules (dense granules, lysosomes and $\alpha$ granules), which reside in the circulating blood, and can themselves secrete granule contents when activated. The most abundant particles are $\alpha$ granules, which contain a large number of immunomodulatory cytokines and chemokines, including platelet factor 4 (PF-4), $\beta$-thromboglobulin ( $\beta$-TG), P-selectin, macrophage inflammatory protein $1 \alpha$ and chemokine CCL5, which have pro-inflammatory functions (16). Dense granules store ADP, ATP and calcium ions, among other components (17). Lysosomes contain acid hydrolases that play a role in phagocytic cellular components (18). It has been shown that P-selectin expression is upregulated in inflammatory diseases, such as hypertension and atherosclerosis (19), and platelet-derived P-selectin plays a major role in the inflammatory and endothelial proliferative response after arterial injury $(20,21)$. Platelets can also be involved in the progression of rheumatoid arthritis by promoting platelet particle release through the activation of type VI collagen binding to CD41 on the platelet surface (22).
Immune system receptors, including TLRs 1-7 and 9, are present on the platelet surface. TLRs are a family of pattern recognition receptors expressed by phagocytes, such as neutrophils, macrophages and dendritic cells (23), which recognize the $\mathrm{Fc}$ receptor of immunoglobulins, and thus participate in allergic inflammation (24), and promote atherosclerosis and inflammation by inhibiting T-reg cell recruitment through the activation of CD40 (25). Platelets also express thrombin (PAR1, 3 and 4), ADP (P2Y 1 and P2Y $\mathrm{Y}_{12}$ ), and the thromboxane A2 (TXA2) receptors thromboxane receptor (TP)- $\alpha$ and TP- $\beta$, which when bound to their respective ligands, can lead to platelet aggregation and the secretion of bioactive mediators, which are involved in the progression of inflammatory diseases (26).

Platelets can also be activated by direct contact, such as platelets interacting with neutrophils via CD62P and with $\mathrm{B}$ cells via pattern recognition receptors. They also interact with T cells via the CD40/CD40L complex, and with endothelial cells and erythrocytes via the integrin receptor (27). An in vitro study by Danese et al (28) showed that platelets rapidly adhere to human intestinal microvascular endothelial cells when co-incubated with IL-1 $\beta$, stimulating the expression of vascular cell adhesion molecule 1 and intercellular adhesion molecule-1 (ICAM-1; two major leukocyte receptors) on the surface of endothelial cells, and the secretion of the neutrophil chemokine IL-8, which plays an important role in inflammatory bowel disease.

In addition, the pathogenic mechanisms of platelets in various lung diseases have been elucidated. Higher expression of P-selectin, PF-4 and $\beta$-TG in the platelets of asthma patients, when compared to that in controls, has been revealed by Kasperska et al (29). High expression of TXA2 and soluble (s)CD40L during platelet hyperfunction was found in pulmonary cystic fibrosis disease, as summarized by O'Sullivan and Michelson (30). In summary, it can be concluded that platelets are not only widely recognized as a major player in hemostasis and thrombosis, but also as immune cells involved in the inflammatory response of the body, and can mediate tissue damage.

\section{Platelet activation is involved in the pathogenic mechanism of ALI}

Megakaryocytes are essential precursor cells for platelet production, and the lungs are a reservoir of these cells $(31,32)$; therefore, platelets are present in large numbers in pulmonary circulation. Despite the significant protective role of platelets in hemostasis and inflammatory defense, a large body of experimental and clinical data shows that platelets play a dual role in ALI. On the one hand, platelets help to maintain the integrity of the alveolar capillary base barrier, which selectively limits the extravascular transfer of water, proteins and red blood cells (33), and contributes to pulmonary vascular repair (34). On the other hand, platelets can also regulate ALI/ARDS pathogenic processes through complex mechanisms, such as neutrophil recruitment, macrophage-dependent inflammation and modulation of alveolar capillary permeability (35). The pathogenic role of platelets depends on the balance of the inflammatory response in the body. When the body is in a normal healthy state, platelets can maintain the 
stability of the vascular endothelium and play an important role in maintaining the healthy state of the body. When an organism is in a diseased state, platelets are activated in various forms, leading to a series of inflammatory reactions that cause damage to the organism. Lê et al (36) showed that the mouse ALI model relies heavily on platelet activation, and that in a mouse model of ALI, several activated platelets were detected in the lungs and plasma compared to the levels in the normal control mice. Looney et al (37) found that depleted platelets protect mice from severe lung injury, and when platelet activation was blocked with aspirin, thromboxane production was reduced, as was lung injury and mortality. There are several causes of ALI, and the pathogenesis is not completely the same in different possible stages; that is, the mechanism of platelet action in ALI induced by different causes vaires itself. For example, Yasui et al (38) showed that the occurrence of lung injury may be due to platelet dysfunction in a rat model of blunt traumatic brain injury, whereas Clark et al (39) found that increased platelet-neutrophil binding leads to the occurrence of lung injury in a model of sepsis due to bacterial infection. To conclude, platelets are an important component involved in the progression of ALI. In this section, the mechanisms through which platelet factors are involved in ALI in terms of immune regulation of platelet secretion, receptor-ligand signaling related to platelet activation, and direct contact interactions between platelets and related cells are discussed.

Platelets secrete active substances. The binding of exogenous activators to platelet membrane-bound proteins induces the secretion of platelet granules, such as dense granules, lysosomes and $\alpha$ granules, which contain adhesion molecules, factors related to coagulation and fibrinolysis, as well as the secretion of calcium and pyrophosphate (16). The expression of adhesion molecules, such as P-selectin, CD31, GP IIb/IIIa, fibronectin and thrombin-reactive proteins, can be upregulated to participate in the development of ALI (40). When ALI occurs, platelets are activated in the pulmonary microvasculature, leading to platelet-microparticle (PMP) secretion. Studies have shown that under inflammatory conditions, the release of PMPs can activate immune cells, such as neutrophils and non-immune cells, to synthesize and secrete several enzymes that promote the progression of inflammation, such as proteases, and active pro-inflammatory soluble mediators including IL-1, TNF and complement $\mathrm{C} 5 \mathrm{a} / \mathrm{C} 5 \mathrm{a}$ receptors, which further cause tissue damage $(41,42)$. Meanwhile, PMPs contain large amounts of aminophospholipids, substrates of phospholipase A2, and are associated with the production of lysophosphatidic acid, which in turn affects the inflammatory process of platelets and is involved in the pathogenic role of platelets in ALI (43). PMPs also support the transcellular transport of arachidonic acid, upregulate the expression of endothelial cyclooxygenase 2 and ICAM-1, and regulate the interface between endothelial cells and platelets $(44,45)$. This can lead to impairment of the alveolar-capillary barrier, increased vascular and alveolar epithelial permeability, and the influx of protein-rich fluid into the intercellular stroma and alveoli, which is the primary pathological mechanism of ALI (46). Furthermore, platelets are stimulated to secrete the pro-inflammatory mediator TXA2, which is an important mediator of platelet-neutrophil aggregation when ALI occurs (47), and increased platelet-neutrophil aggregation aggravates ALI damage (48). Platelets secrete vascular endothelial growth factor (VEGF), a powerful angiogenic factor that plays a key role in regulating angiogenesis, both by inducing vascular endothelial cell proliferation, and by promoting cell survival through the induction of the anti-apoptotic proteins Bcl-2 and A1 (49). VEGF has the ability to increase microvascular permeability by a factor of 20,000 compared to histamine, and therefore induces an increase in endothelial permeability (50). Endothelial permeability plays a key role in the pathogenesis of ALI; therefore, it is hypothesized that platelet activation-induced VEGF secretion may also play an important role in the progression of ALI/ARDS.

CD40L is expressed at a low level in unstimulated platelets, but can be rapidly upregulated on the platelet surface after platelet stimulation. The platelet surface-expressed CD40L is subsequently cleaved within minutes to hours, producing a soluble fragment called sCD40L (51). The expression of platelet-associated CD40L on the platelet surface and exposure to CD40 receptor-containing vascular cells can initiate various inflammatory responses, including the expression of inflammatory adhesion receptors (such as E-selectin, vascular cell adhesion molecule-1 and ICAM-1), the expression of tissue factors, and the release of chemokines (monocyte chemotactic protein-1, IL-6 and IL-8) (52), all of which may contribute to the development of ALI. sCD40L not only induces monocytes to secrete the neutrophil chemotactic agent MIP-2 but also interacts with membrane CD40 to directly activate neutrophils (53); therefore, it is hypothesized that SCD40L can lead to the substantial accumulation and activation of neutrophils, accelerating the course of ALI. However, the direct role of sCD40L in the pathogenesis of ALI remains unclear. In summary, platelets as inflammatory cells can be involved in the process of ALI through the synthesis and secretion of a large number of active substances (Fig. 1).

Platelet receptor ligand signaling pathway. Although platelets are widely known for their hemostatic and clotting effects, they are also critical for growth and development, host defense, inflammation and tissue repair. Several of these processes are regulated by the immunoglobulin-like receptor glycoprotein VI (GPVI) and C-type lectin receptor 2 (CLEC-2), which act based on signaling from the immunoreceptor tyrosine-based activation motif (ITAM) (54). The ITAM receptor signaling pathway is required for platelet activation by the extracellular matrix and extravascular cells. Platelets express two types of ITAM receptors, GPVI receptor for collagen and laminin and CLEC-2 receptor for podoplanin (PDPN) (55) CLEC-2 is a type II membrane protein that is highly expressed on megakaryocytes and platelets, and expressed at low levels on peripheral blood neutrophils, mediating phagocytosis and the release of pro-inflammatory cytokines, including TNF- $\alpha$ (56). CLEC-2 interacts with PDPN to activate platelets via the tyrosine kinase signaling pathway, and in addition, GPVI interacts with ligands (collagen) to activate platelets via the Syk pathway $(57,58)$. However, protein hydrolysis in the ITAM region causes the activation of downstream protein phosphorylation, release of calcium ions into the cytoplasm, activation of ATPase, catabolism of ATP, and supply of energy for platelet activation and release $(59,60)$. These reactions may be involved 


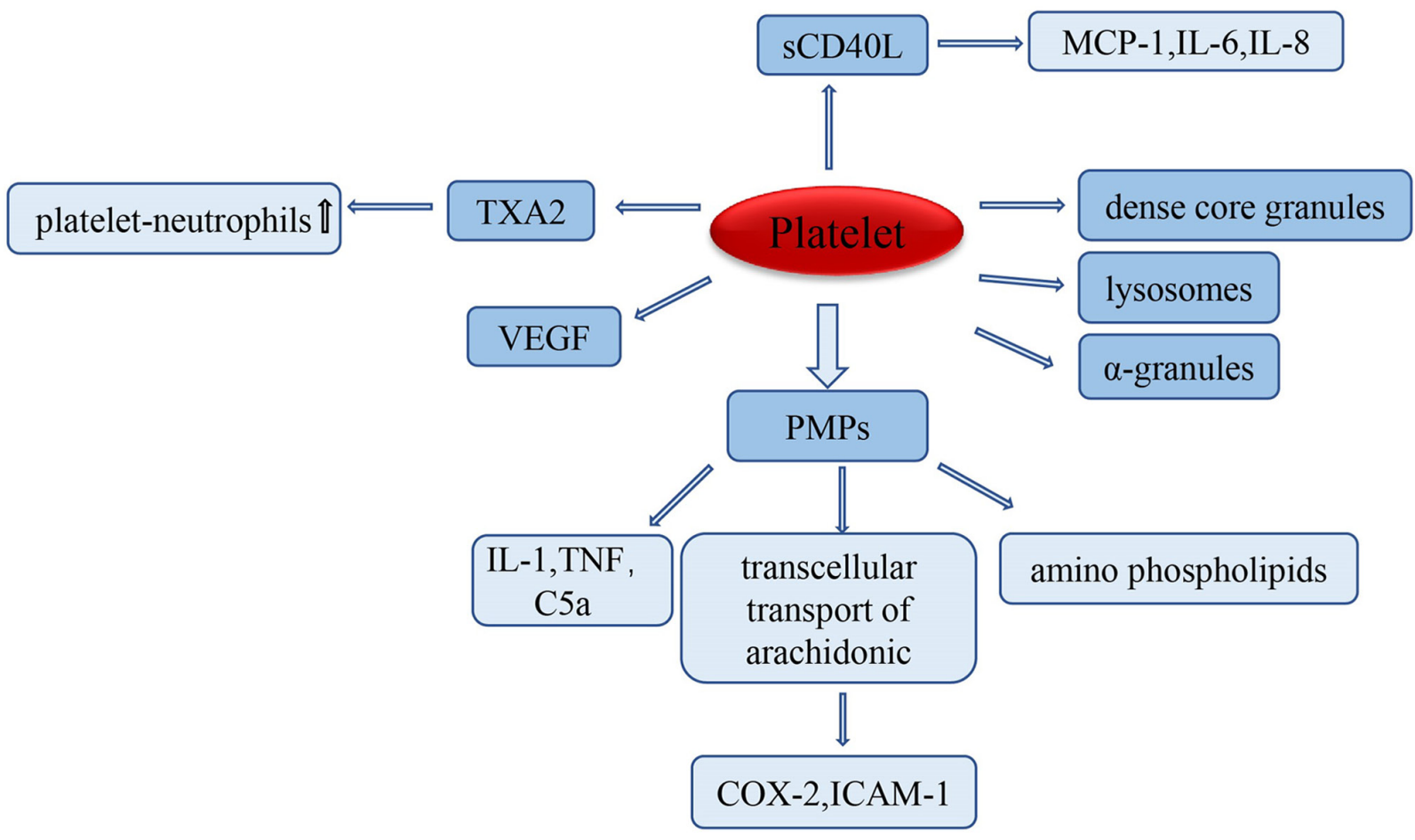

Figure 1. Secretory reactive substances released from platelets that modulate lung injury. VEGF, vascular endothelial growth factor; PMP, platelet-microparticle; TXA2, thromboxane A2; COX-2, cyclooxygenase 2; ICAM-1, intercellular adhesion molecule-1.

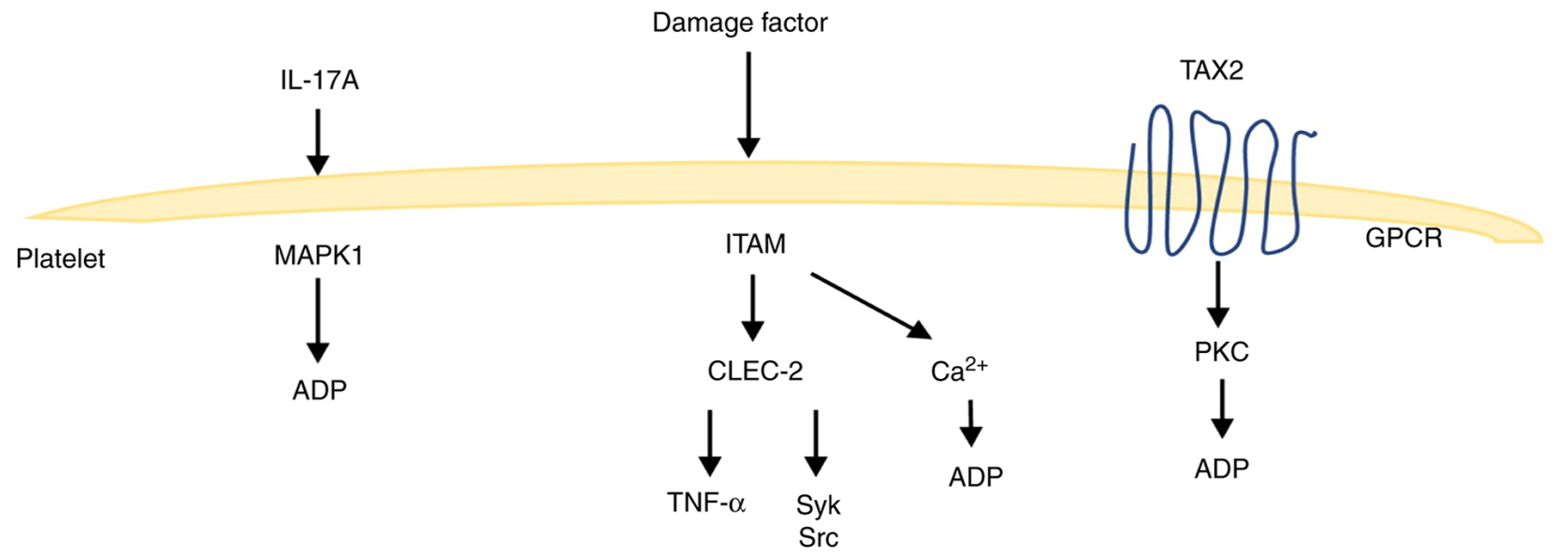

Figure 2. Platelet receptor ligand signaling pathway activation regulates lung injury. ITAM, immunoreceptor tyrosine-based activation motif; CLEC-2, C-type lectin-like receptor 2; MAPK1, mitogen-activated protein kinase 1; GPCR, G protein-coupled receptor; ADP, adenosine diphosphate; PKC, protein kinase C; Syk, spleen tyrosine kinase.

in the progression of ALI, but the exact mechanism underlying this process needs to be elucidated by further studies.

Platelets express the thromboxane receptor $\mathrm{TP} \alpha$ on their surface, and both TP $\alpha$ and TP $\beta$ on endothelial cells activate endothelial cells and G-protein-dependent downstream pathways, such as increased expression of the PKC pathway-dependent adhesion molecule ICAM-1 (61). Meanwhile, TXA2 binding to $\mathrm{G}$ protein-coupled TPs can lead to a wide range of cellular responses, including integrin activation, platelet aggregation, smooth muscle cell contraction and increased vascular permeability, which can be involved in the development of ALI (62). IL-17A can also promote ADP-induced platelet activation through the extracellular signal-regulated kinase 2 (ERK2; also known as MAPK1) signaling pathway, which induces platelet responses involved in inflammatory responses (63). Moreover, the link between platelet-related signaling pathways and ALI needs to be further elucidated (Fig. 2).

Direct contact between platelets and other types of cells. Platelets are in a resting state under normal conditions, but can be activated indirectly or directly during ALI to exert their corresponding biological effects. In a model of LPS-induced lung injury, platelet activation mediates an increase in platelet surface CD62P and GPIIb/IIIa expression through the activation of TLR4. Additionally, CD62P is a key ligand for platelet binding to neutrophils and monocytes (39), which can enhance 


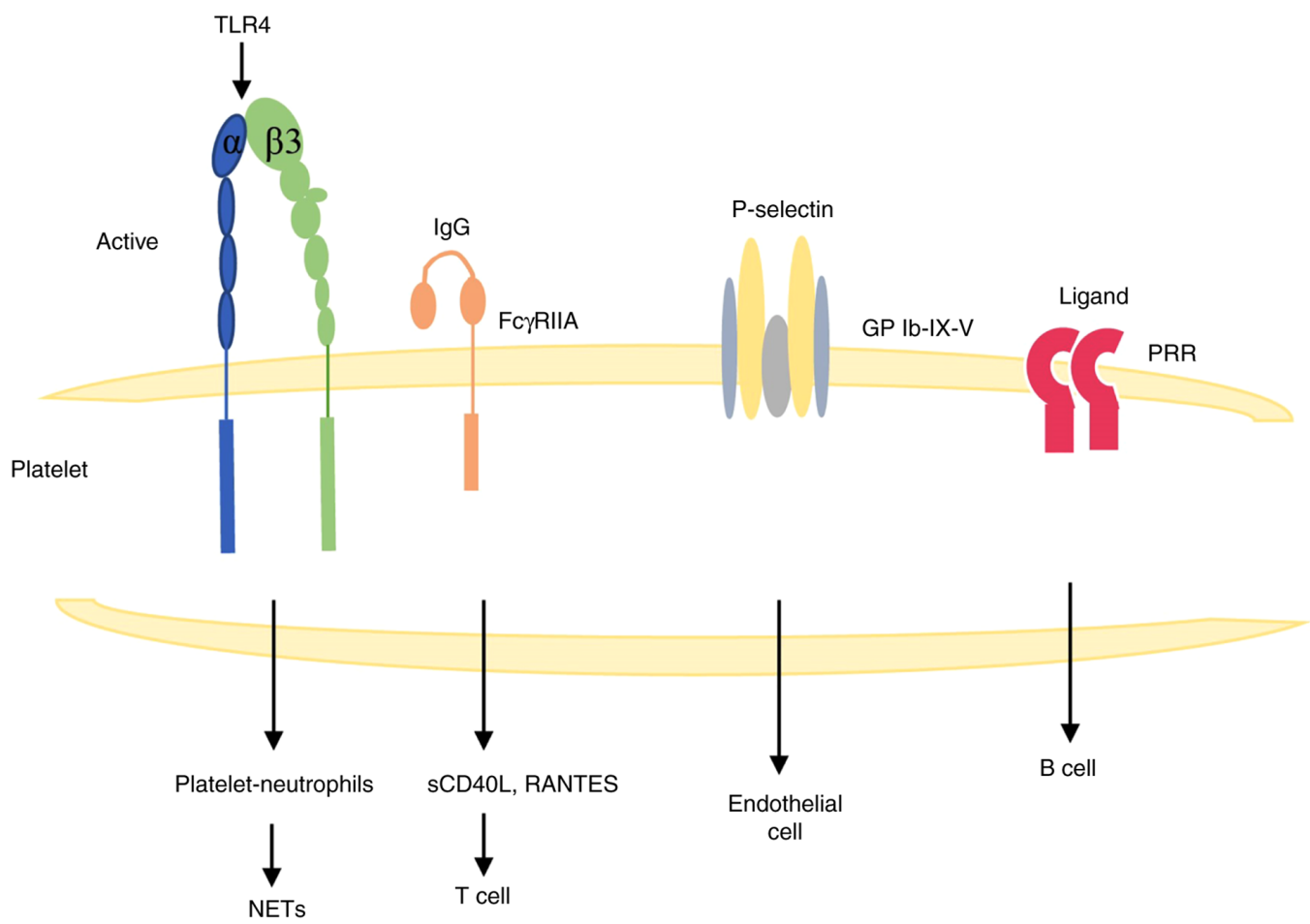

Figure 3. Through direct contact with cells, Platelets modulate lung injury. NETs, neutrophil extracellular traps; PRR, pattern recognition receptor; RANTES, regulated upon activation, normal $\mathrm{T}$ cell expressed and secreted factor.

platelet-neutrophil interactions during ALI, leading to the production of neutrophil extracellular traps (NETs) (64). NETs are associated with a type of cell death distinct from apoptosis and necrosis, a process known as NETosis (65), and the mechanism of their formation is not fully understood. They may provide the conditions for platelet capture and thrombosis in the pulmonary microcirculation through exposure to their extracellular histones, neutrophil granule proteins and extracellular DNA networks, ultimately leading to pulmonary endothelial injury and participating in the progression of ALI $(66,67)$. Therefore, targeting NETs could be a potential therapeutic modality for the treatment of lung injury.

ALI leads to vascular injury, and various platelet agonists and intrinsic factors lead to platelet activation. It has been shown that platelet Fc $\gamma$ RIIA can bind to endocrine $\operatorname{IgG}$ complexes and release large amounts of sCD40L and RANTES (68), where sCD40L interacts with $\mathrm{T}$ cells through direct contact with the CD40/CD40L complex, further supporting the involvement of platelets in the inflammatory response $(69,70)$. Platelets can interact with B cells via PRRs, and through PRR-mediated cell activation, inflammatory signaling transduction and apoptosis induction occur, which are involved in the progression of ALI $(25,71)$. Platelets can also interact with P-selectin-expressing endothelial cells via the integrin receptor GPIb-IX-V to mediate the endothelial cell inflammatory response (72). All of these factors can further enhance the inflammatory response to activate platelets, and platelets play an important role in ALI (Fig. 3).

\section{Conclusion and future prospects}

As a disease associated with high morbidity rates, and poor diagnostic and prognostic measures, ALI has no definite strategy for prevention and treatment; it can only be improved/prevented by treating the primary disease, controlling the systemic inflammatory response, and improving hypoxemia with supportive therapy using non-invasive or invasive ventilators. Owing to the poor prognosis of patients under the current treatment strategies for ALI, and due to the persistent pulmonary dysfunction observed in a significant proportion of survivors, patients have a poor quality of life. Therefore, it is necessary to explore a feasible means of intervention or treatment for ALI to save patients' lives and improve their quality of life. Previous studies have shown that the pathogenesis of ALI is centered on an inflammatory response, and there is now increasing evidence that platelets can act as inflammatory cells and participate in the progression of various inflammatory diseases through various pathways, such as the participation of platelets in the progression of rheumatoid arthritis by amplifying inflammation through collagen-dependent particles and mediating cerebral malaria through PF-4 (22,73). Platelets are also involved in the development of several types of lung diseases; for example, the high expression of P-selectin, PF-4 and $\beta$-TG in platelets, as discussed in this review, can increase the severity of disease in asthma patients (29). Platelet function is hyper-activated in pulmonary cystic fibrosis with high expression of TXA2 and sCD40L (30). Furthermore, platelets also serve a considerable role in the progression of ALI, and can influence the course of ALI through a variety of pathways, such as the immunoregulation of platelet secretion, receptor-ligand signaling associated with platelet activation, and direct contact reactions between platelets and associated cells. Several studies have now found that anti-platelet reagents can reduce the severity of ALI; for example Hagiwara et al (74) showed that platelet inhibition with clopidogrel reduces LPS-induced ALI in rats by inhibiting the P2 $\mathrm{Y}_{12}$ receptor. In another experiment, Asaduzzaman et al (75) 
also found that platelet inhibition reduces lung injury by inhibiting neutrophil-platelet aggregation. Cognasse et al (76) illustrated that the use of an anti-GPIb $\alpha$ antibody, which was used as a specific platelet inhibitor in a transfusion-associated ALI model, reduced the extent of lung injury in a model of ALI. Moreover, with the recent COVID-19 pandemic, it has been found that during the course of pneumonia, anti-platelet use was associated with a lower risk of severe disease (77). Furthermore, at present, the primary genetic changes involved in lung diseases are pulmonary fibrosis caused by paraquat and various lung cancers (78-81); however, the genetic alterations to platelets in ALI do not seem to be involved, based on current studies (82-86), and these need to be further analyzed by gene microarray analysis, which is also the direction that our lab will take for future research.

This review is only a summary of the possible involvement of platelets in the progression of ALI. The immune mechanisms by which platelets promote tissue damage and regulate ALI are not yet fully understood, and further studies are needed to elucidate the etiological roles of platelets as both mediators of ALI and effector cells of ALI. Novel targets to intervene and manage ALI may be discovered by exploring the mechanisms by which platelets regulate or mediate lung injury, and intervening in the relevant pathways in advance or inhibiting platelet activation, thus blocking the vicious cycle. Moreover, future studies should also focus on the mechanisms by which platelets act as inflammatory cells during disease progression.

\section{Acknowledgements}

Not applicable.

\section{Funding}

The present study was funded by the National Natural Science Foundation of China (grant no. 31801192).

\section{Availability of data and materials}

Not applicable.

\section{Authors' contributions}

YX and JP conceived the article. YX drafted the manuscript and constructed the figures. JP revised the manuscript and the figures. YYH, QCC, SP and SN analyzed the relevant literature. LFZ edited the manuscript. All authors read and approved the final manuscript. Data authentication is not applicable.

\section{Ethics approval and consent to participate}

Not applicable.

\section{Patient consent for publication}

Not applicable.

\section{Competing interests}

The authors declare that they have no competing interests.

\section{References}

1. Bernard GR, Artigas A, Brigham KL, Carlet J, Falke K, Hudson L, Lamy M, Legall JR, Morris A and Spragg R: The American-European consensus conference on ARDS. definitions, mechanisms, relevant outcomes, and clinical trial coordination. Am J Respir Crit Care Med 149: 818-824, 1994.

2. Phua J, Badia JR, Adhikari NK, Friedrich JO, Fowler RA, Singh JM, Scales DC, Stather DR, Li A, Jones A, et al: Has mortality from acute respiratory distress syndrome decreased over time?: A systematic review. Am J Respir Crit Care Med 179: 220-227, 2009.

3. Jenne $\mathrm{CN}$ and Kubes P: Platelets in inflammation and infection. Platelets 26: 286-292, 2015.

4. Maouia A, Rebetz J, Kapur R and Semple JW: The immune nature of platelets revisited. Transfus Med Rev 34: 209-220, 2020.

5. Smyth SS, McEver RP, Weyrich AS, Morrell CN, Hoffman MR, Arepally GM, French PA, Dauerman HL and Becker RC; 2009 Platelet Colloquium Participants: Platelet functions beyond hemostasis. J Thromb Haemost 7: 1759-1766, 2009.

6. Cox D, Kerrigan SW and Watson SP: Platelets and the innate immune system: Mechanisms of bacterial-induced platelet activation. J Thromb Haemost 9: 1097-1107, 2011.

7. Pugin J, Verghese G, Widmer MC and Matthay MA: The alveolar space is the site of intense inflammatory and profibrotic reactions in the early phase of acute respiratory distress syndrome. Crit Care Med 27: 304-312, 1999.

8. Ware LB and Matthay MA: The acute respiratory distress syndrome. N Engl J Med 342: 1334-1349, 2000.

9. Grommes J and Soehnlein O: Contribution of neutrophils to acute lung injury. Mol Med 17: 293-307, 2011.

10. Nagase T, Ishii S, Kume K, Uozumi N, Izumi T, Ouchi Y and Shimizu T: Platelet-activating factor mediates acid-induced lung injury in genetically engineered mice. J Clin Invest 104: 1071-1076, 1999.

11. Zemans RL, Colgan SP and Downey GP: Transepithelial migration of neutrophils: Mechanisms and implications for acute lung injury. Am J Respir Cell Mol Biol 40: 519-535, 2009.

12. Bhatia M, Zemans RL and Jeyaseelan S: Role of chemokines in the pathogenesis of acute lung injury. Am J Respir Cell Mol Biol 46: 566-572, 2012.

13. Saffarzadeh M, Juenemann C, Queisser MA, Lochnit G, Barreto G, Galuska SP, Lohmeyer J and Preissner KT: Neutrophil extracellular traps directly induce epithelial and endothelial cell death: A predominant role of histones. PLoS One 7: e32366, 2012.

14. Jeyaseelan S, Chu HW, Young SK, Freeman MW and Worthen GS: Distinct roles of pattern recognition receptors CD14 and Toll-like receptor 4 in acute lung injury. Infect Immun 73: 1754-1763, 2005.

15. Huang JJ, Xia J, Huang LL and Li YC: HIF-1 $\alpha$ promotes NLRP3 inflammasome activation in bleomycin-induced acute lung injury. Mol Med Rep 20: 3424-3432, 2019.

16. Rendu F and Brohard-Bohn B: The platelet release reaction: Granules' constituents, secretion and functions. Platelets 12: 261-273, 2001.

17. Meng R, Wang Y, Yao Y, Zhang Z, Harper DC, Heijnen HF, Sitaram A, Li W, Raposo G, Weiss MJ, et al: SLC35D3 delivery from megakaryocyte early endosomes is required for platelet dense granule biogenesis and is differentially defective in Hermansky-Pudlak syndrome models. Blood 120: 404-414, 2012.

18. Heijnen $\mathrm{H}$ and van der Sluijs P: Platelet secretory behaviour: As diverse as the granules ... or not? J Thromb Haemost 13: 2141-2151, 2015.

19. Koyama H, Maeno T, Fukumoto S, Shoji T, Yamane T, Yokoyama H, Emoto M, Shoji T, Tahara H, Inaba M, et al: Platelet P-selectin expression is associated with atherosclerotic wall thickness in carotid artery in humans. Circulation 108: 524-529, 2003.

20. Wysokinski WE, Cohoon KP, Melduni RM, Mazur M, Ammash N, Munger T, Konik E, McLeod T, Gosk-Bierska I and McBane RD: Association between P-selectin levels and left atrial blood stasis in patients with nonvalvular atrial fibrillation. Thromb Res 172: 4-8, 2018

21. Wang K, Zhou X, Zhou Z, Mal N, Fan L, Zhang M, Lincoff AM, Plow EF, Topol EJ and Penn MS: Platelet, not endothelial, P-selectin is required for neointimal formation after vascular injury. Arterioscler Thromb Vasc Biol 25: 1584-1589, 2005. 
22. Boilard E, Nigrovic PA, Larabee K, Watts GF, Coblyn JS, Weinblatt ME, Massarotti EM, Remold-O'Donnell E, Farndale RW, Ware J and Lee DM: Platelets amplify inflammation in arthritis via collagen-dependent microparticle production. Science 327: 580-583, 2010.

23. Semple JW, Italiano JE Jr and Freedman J: Platelets and the immune continuum. Nat Rev Immunol 11: 264-274, 2011.

24. Hasegawa S, Tashiro N, Matsubara T, Furukawa S and Ra C: A comparison of FcepsilonRI-mediated RANTES release from human platelets between allergic patients and healthy individuals. Int Arch Allergy Immunol 125 (Suppl 1): S42-S47, 2001

25. Lapchak PH, Ioannou A, Kannan L, Rani P, Dalle Lucca JJ and Tsokos GC: Platelet-associated CD40/CD154 mediates remote tissue damage after mesenteric ischemia/reperfusion injury. PLoS One 7: e32260, 2012.

26. Ghoshal K and Bhattacharyya M: Overview of platelet physiology: Its hemostatic and nonhemostatic role in disease pathogenesis. ScientificWorldJournal 2014: 781857, 2014.

27. Yeaman MR: Platelets: At the nexus of antimicrobial defence. Nat Rev Microbiol 12: 426-437, 2014.

28. Danese S, de la Motte C, Sturm A, Vogel JD, West GA, Strong SA Katz JA and Fiocchi C: Platelets trigger a CD40-dependent inflammatory response in the microvasculature of inflammatory bowel disease patients. Gastroenterology 124: 1249-1264, 2003.

29. Kasperska-Zajac A, Brzoza Z and Rogala B: Seasonal changes in platelet activity in pollen-induced seasonal allergic rhinitis and asthma. J Asthma 45: 485-487, 2008.

30. O'Sullivan BP and Michelson AD: The inflammatory role of platelets in cystic fibrosis. Am J Respir Crit Care Med 173: 483-490, 2006.

31. Weyrich AS and Zimmerman GA: Platelets in lung biology. Annu Rev Physiol 75: 569-591, 2013.

32. Lefrançais E and Looney MR: Platelet biogenesis in the lung circulation. Physiology (Bethesda) 34: 392-401, 2019.

33. Tabuchi A and Kuebler WM: Endothelium-platelet interactions in inflammatory lung disease. Vascul Pharmacol 49: 141-150, 2008.

34. Ho-Tin-Noé B, Demers M and Wagner DD: How platelets safeguard vascular integrity. J Thromb Haemost 9 (Suppl 1): S56-S65, 2011

35. Middleton EA, Weyrich AS and Zimmerman GA: Platelets in pulmonary immune responses and inflammatory lung diseases. Physiol Rev 96: 1211-1259, 2016.

36. Lê VB, Schneider JG, Boergeling Y, Berri F, Ducatez M, Guerin JL, Adrian I, Errazuriz-Cerda E, Frasquilho S, Antunes L, et al: Platelet activation and aggregation promote lung inflammation and influenza virus pathogenesis. Am J Respir Crit Care Med 191: 804-819, 2015

37. Looney MR, Nguyen JX, Hu Y, Van Ziffle JA, Lowell CA and Matthay MA: Platelet depletion and aspirin treatment protect mice in a two-event model of transfusion-related acute lung injury. J Clin Invest 119: 3450-3461, 2009.

38. Yasui H, Donahue DL, Walsh M, Castellino FJ and Ploplis VA: Early coagulation events induce acute lung injury in a rat model of blunt traumatic brain injury. Am J Physiol Lung Cell Mol Physiol 311: L74-L86, 2016.

39. Clark SR, Ma AC, Tavener SA, McDonald B, Goodarzi Z Kelly MM, Patel KD, Chakrabarti S, McAvoy E, Sinclair GD, et al: Platelet TLR4 activates neutrophil extracellular traps to ensnare bacteria in septic blood. Nat Med 13: 463-469, 2007.

40. Zarbock A, Polanowska-Grabowska RK and Ley K Platelet-neutrophil-interactions: Linking hemostasis and inflammation. Blood Rev 21: 99-111, 2007.

41. Nurden AT: Platelets, inflammation and tissue regeneration. Thromb Haemost 105 (Suppl 1): S13-S33, 2011

42. Xie RF, Hu P, Wang ZC, Yang J, Yang YM, Gao L, Fan HH and Zhu YM: Platelet-derived microparticles induce polymorphonuclear leukocyte-mediated damage of human pulmonary microvascular endothelial cells. Transfusion 55: 1051-1057, 2015.

43. Barry OP, Pratico D, Lawson JA and FitzGerald GA: Transcellular activation of platelets and endothelial cells by bioactive lipids in platelet microparticles. J Clin Invest 99: 2118-2127, 1997.

44. Bulut D, Becker V and Mügge A: Acetylsalicylate reduces endothelial and platelet-derived microparticles in patients with coronary artery disease. Can J Physiol Pharmacol 89: 239-244, 2011.

45. Zhou Q, Lian Y, Zhang Y, Li L, Li H, Shen D, Zhou Y, Zhang M, Lu Y, Liu J, et al: Platelet-derived microparticles from recurrent miscarriage associated with antiphospholipid antibody syndrome influence behaviours of trophoblast and endothelial cells. Mol Hum Reprod 25: 483-494, 2019.
46. Bhattacharya $\mathrm{J}$ and Matthay MA: Regulation and repair of the alveolar-capillary barrier in acute lung injury. Annu Rev Physiol 75: 593-615, 2013.

47. Zarbock A, Singbartl K and Ley K: Complete reversal of acid-induced acute lung injury by blocking of platelet-neutrophil aggregation. J Clin Invest 116: 3211-3219, 2006.

48. Bdeir K, Gollomp K, Stasiak M, Mei J, Papiewska-Pajak I, Zhao G, Worthen GS, Cines DB, Poncz M and Kowalska MA: Platelet-specific chemokines contribute to the pathogenesis of acute lung injury. Am J Respir Cell Mol Biol 56: 261-270, 2017.

49. Medford AR and Millar AB: Vascular endothelial growth factor (VEGF) in acute lung injury (ALI) and acute respiratory distress syndrome (ARDS): Paradox or paradigm? Thorax 61: 621-626, 2006.

50. Barratt S, Medford AR and Millar AB: Vascular endothelial growth factor in acute lung injury and acute respiratory distress syndrome. Respiration 87: 329-342, 2014.

51. André P, Nannizzi-Alaimo L, Prasad SK and Phillips DR: Platelet-derived CD40L: The switch-hitting player of cardiovascular disease. Circulation 106: 896-899, 2002.

52. Henn V, Slupsky JR, Gräfe M, Anagnostopoulos I, Förster R, Müller-Berghaus G and Kroczek RA: CD40 ligand on activated platelets triggers an inflammatory reaction of endothelial cells. Nature 391: 591-594, 1998.

53. Rahman M, Zhang S, Chew M, Ersson A, Jeppsson B and Thorlacius H: Platelet-derived CD40L (CD154) mediates neutrophil upregulation of Mac-1 and recruitment in septic lung injury. Ann Surg 250: 783-790, 2009.

54. Coxon CH, Geer MJ and Senis YA: ITIM receptors: More than just inhibitors of platelet activation. Blood 129: 3407-3418, 2017.

55. Watson SP, Herbert JM and Pollitt AY: GPVI and CLEC-2 in hemostasis and vascular integrity. J Thromb Haemost 8: 1456-1467, 2010.

56. Kerrigan AM, Dennehy KM, Mourão-Sá D, Faro-Trindade I, Willment JA, Taylor PR, Eble JA, Reis e Sousa C and Brown GD: CLEC-2 is a phagocytic activation receptor expressed on murine peripheral blood neutrophils. J Immunol 182: 4150-4157, 2009.

57. Badolia R, Kostyak JC, Dangelmaier C and Kunapuli SP: Syk activity is dispensable for platelet GP1b-IX-V signaling. Int J Mol Sci 18: 1238, 2017.

58. Suzuki-Inoue K: Roles of the CLEC-2-podoplanin interaction in tumor progression. Platelets: Jun 4, 2018 (Epub ahead of print). doi: 10.1080/09537104.2018.1478401.

59. Quintanilla M, Montero-Montero L, Renart J and Martín-Villar E: Podoplanin in inflammation and cancer. Int J Mol Sci 20: 707, 2019.

60. Mammadova-Bach E, Gil-Pulido J, Sarukhanyan E, Burkard P, Shityakov S, Schonhart C, Stegner D, Remer K, Nurden P, Nurden AT, et al: Platelet glycoprotein VI promotes metastasis through interaction with cancer cell-derived galectin-3. Blood 135: 1146-1160, 2020.

61. Huang JS, Ramamurthy SK, Lin X and Le Breton GC: Cell signalling through thromboxane A2 receptors. Cell Signal 16: 521-533, 2004.

62. Goff CD, Corbin RS, Theiss SD, Frierson HF Jr, Cephas GA, Tribble CG, Kron IL and Young JS: Postinjury thromboxane receptor blockade ameliorates acute lung injury. Ann Thorac Surg 64: 826-829, 1997

63. Zhang S, Yuan J, Yu M, Fan H, Guo ZQ, Yang R, Guo HP, Liao YH and Wang M: IL-17A facilitates platelet function through the ERK2 signaling pathway in patients with acute coronary syndrome. PLoS One 7: e40641, 2012.

64. Caudrillier A, Kessenbrock K, Gilliss BM, Nguyen JX, Marques MB, Monestier M, Toy P, Werb Z and Looney MR: Platelets induce neutrophil extracellular traps in transfusion-related acute lung injury. J Clin Invest 122: 2661-2671, 2012

65. Holm S, Kared H, Michelsen AE, Kong XY, Dahl TB, Schultz NH, Nyman TA, Fladeby C, Seljeflot I, Ueland T, et al: Immune complexes, innate immunity, and NETosis in ChAdOx1 vaccine-induced thrombocytopenia. Eur Heart J 42: 4064-4072, 2021.

66. Brinkmann V, Reichard U, Goosmann C, Fauler B, Uhlemann Y, Weiss DS, Weinrauch Y and Zychlinsky A: Neutrophil extracellular traps kill bacteria. Science 303: 1532-1535, 2004.

67. Fuchs TA, Brill A, Duerschmied D, Schatzberg D, Monestier M, Myers DD Jr, Wrobleski SK, Wakefield TW, Hartwig JH and Wagner DD: Extracellular DNA traps promote thrombosis. Proc Natl Acad Sci USA 107: 15880-15885, 2010. 
68. Worth RG, Chien CD, Chien P, Reilly MP, McKenzie SE and Schreiber AD: Platelet FcgammaRIIA binds and internalizes IgG-containing complexes. Exp Hematol 34: 1490-1495, 2006.

69. Antczak AJ, Vieth JA, Singh N and Worth RG: Internalization of IgG-coated targets results in activation and secretion of soluble CD40 ligand and RANTES by human platelets. Clin Vaccine Immunol 18: 210-216, 2011.

70. Semple JW, Rebetz J, Maouia A and Kapur R: An update on the pathophysiology of immune thrombocytopenia. Curr Opin Hematol 27: 423-429, 2020.

71. Sowa JM, Crist SA, Ratliff TL and Elzey BD: Platelet influence on T- and B-cell responses. Arch Immunol Ther Exp (Warsz) 57: 235-241, 2009.

72. Romo GM, Dong JF, Schade AJ, Gardiner EE, Kansas GS Li CQ, McIntire LV, Berndt MC and López JA: The glycoprotein Ib-IX-V complex is a platelet counterreceptor for P-selectin. J Exp Med 190: 803-814, 1999.

73. Srivastava K, Cockburn IA, Swaim A, Thompson LE, Tripathi A, Fletcher CA, Shirk EM, Sun H, Kowalska MA, Fox-Talbot K, et al: Platelet factor 4 mediates inflammation in experimental cerebral malaria. Cell Host Microbe 4: 179-187, 2008.

74. Hagiwara S, Iwasaka H, Hasegawa A, Oyama M, Imatomi R, Uchida $\mathrm{T}$ and Noguchi T: Adenosine diphosphate receptor antagonist clopidogrel sulfate attenuates LPS-induced systemic inflammation in a rat model. Shock 35: 289-292, 2011.

75. Asaduzzaman M, Lavasani S, Rahman M, Zhang S, Braun OO, Jeppsson B and Thorlacius $\mathrm{H}$ : Platelets support pulmonary recruitment of neutrophils in abdominal sepsis. Crit Care Med 37: 1389-1396, 2009.

76. Cognasse F, Tariket S, Hamzeh-Cognasse H, Arthaud CA, Eyraud MA, Bourlet T, Berthelot P, Laradi S, Fauteux-Daniel S and Garraud O: Platelet depletion limits the severity but does not prevent the occurrence of experimental transfusion-related acute lung injury. Transfusion 60: 713-723, 2020.

77. Zhou J, Lee S, Guo CL, Chang C, Liu T, Leung KSK, Wai AKC, Cheung BMY, Tse G and Zhang Q: Anticoagulant or antiplatelet use and severe COVID-19 disease: A propensity score-matched territory-wide study. Pharmacol Res 165: 105473, 2021.
78. Zhu Y, Wang J, Meng X, Xie H, Tan J, Guo X, Han P and Wang R: A positive feedback loop promotes HIF-1 $\alpha$ stability through miR-210-mediated suppression of RUNX3 in paraquat-induced EMT. J Cell Mol Med 21: 3529-3539, 2017.

79. Zhou N, Liu Q, Qi X, Zhang X, Ru Z, Ma Y, Yu T, Zhang M, Li Y, Zhang Y and Cao Z: Paraquat exposure impairs porcine oocyte meiotic maturation. Theriogenology 179: 60-68, 2021

80. Zu Y, Ban J, Xia Z, Wang J, Cai Y, Ping W and Sun W: Genetic variation in a miR-335 binding site in BIRC5 alters susceptibility to lung cancer in Chinese Han populations. Biochem Biophys Res Commun 430: 529-534, 2013.

81. Zuo X, Xu W, Xu M, Tian R, Moussalli MJ, Mao F, Zheng X, Wang J, Morris JS, Gagea M, et al: Metastasis regulation by PPARD expression in cancer cells. JCI Insight 2: e91419, 2017.

82. Zu L, Xue Y, Wang J, Fu Y, Wang X, Xiao G, Hao M, Sun X, Wang Y, Fu G and Wang J: The feedback loop between miR-124 and TGF- $\beta$ pathway plays a significant role in non-small cell lung cancer metastasis. Carcinogenesis 37: 333-343, 2016.

83. Zou W, Chen L, Mao W, Hu S, Liu Y and Hu C: Identification of inflammatory response-related gene signature associated with immune status and prognosis of lung adenocarcinoma. Front Bioeng Biotechnol 9: 772206, 2021.

84. Zou M, Xia S, Zhuang L, Han N, Chu Q, Chao T, Peng P, Chen Y, Gui Q and Yu S: Knockdown of the Bcl-2 gene increases sensitivity to EGFR tyrosine kinase inhibitors in the H1975 lung cancer cell line harboring T790M mutation. Int J Oncol 42: 2094-2102, 2013.

85. Zou K, Tong E, Xu Y, Deng X and Zou L: Down regulation of mammalian target of rapamycin decreases HIF- $1 \alpha$ and survivin expression in anoxic lung adenocarcinoma A549 cell to elemene and/or irradiation. Tumour Biol 35: 9735-9741, 2014.

86. Zong L, Sun Q, Zhang H, Chen Z, Deng Y, Li D and Zhang L: Increased expression of circRNA_102231 in lung cancer and its clinical significance. Biomed Pharmacother 102: 639-644, 2018.

This work is licensed under a Creative Commons Attribution-NonCommercial-NoDerivatives 4.0 International (CC BY-NC-ND 4.0) License. 